$\mathbb{T}$ periodica polytechnica

\author{
Transportation Engineering \\ $39 / 1(2011) 35$ \\ doi: 10.3311/pp.tr.2011-1.01 \\ web: http://www.pp.bme.hu/tr \\ (c) Periodica Polytechnica 2011
}

RESEARCH ARTICLE

\section{The development of large traffic network model}

\author{
Zsuzsanna Bede / Tamás Péter
}

Received 2010-10-27

\begin{abstract}
Our article examines speed and acceleration processes, describing the motion of unique vehicles crossing the large network. We take the real traffic into consideration by obtaining the driving cycle from our macroscopic network model. We grant the traffic changes in the entire network with this model. The unique motion process derived from the model is compared to the real - measured - speed and acceleration processes. In this article we validate our model by getting unique speed and acceleration processes. Based on the acceleration values calculated by the model, we redefine the condition set of the model. Comparing the modeled and measured values, it is clear that there are only some momentary differences. But even these small differences should not be neglected, rather they should be used in the model development, as described in this paper.
\end{abstract}

\section{Keywords}

non-linear large traffic network model · extraction of unique velocity processes

\section{Acknowledgement}

The project presented in this article is supported by OTKA CNK 78168.

This work is connected to the scientific program of the "Development of quality-oriented and harmonized $R+D+I$ strategy and functional model at BME" project. This project is supported by the New Hungary Development Plan (Project ID: TÁMOP4.2.1/B-09/1/KMR-2010-0002).

\section{Zsuzsanna Bede}

Department of Control and Transport Automation, BME, Bertalan L. u. 2., H1111 Budapest, Hungary

e-mail: bede.zsuzsanna@mail.bme.hu

\section{Tamás Péter}

Department of Control and Transport Automation, BME, Bertalan L. u. 2., H1111 Budapest, Hungary

e-mail: tamas.peter@mail.bme.hu

\section{Introduction}

Usually it is hard to get unique vehicle data from large traffic network models. However, if the speed profiles belonging to different routes are available, then the optimal routes can be easily calculated. The model describing large traffic networks can be converted to a real-time track recommender, which calculates the best route with respect to the variation of the traffic. Based on the unique speed processes extracted from the macro models, it is possible to examine the single vehicle's power demand and emission [1].

\section{Measurement and validate of model}

The used model [2]3] is validated by the examination of a real section of Budapest [4 5]. Before starting the examination we have to take into consideration, that the simulated variation of traffic is based on statistical data. Because of this the acceptance of the simulated diagrams depends on the values measured on the road network.

So we drove along the examined route and stored the real speed profiles using a GPS. Comparing the speed diagrams stored during different runs showed that it is impossible to get twice the same profile. The drive cycles must be handled as different realizations of a stochastic process, and can only be examined with a statistical analysis. Keeping this in mind, we compared the simulated and measured data, as shown on Fig. 1 (we indicated the running-time on the horizontal axis).

\section{The results and the examination of accelerations}

We began the comparison of the received speed values with the examination of the vehicle-based speed and power demand distributions. The model is validated and provides unique speed processes, that are identical to the real measured ones.

We analyzed the simulated speed profiles with respect to the acceleration. The acceleration profiles show extreme values over the vehicle's capabilities in 10-15 points during the examined 4 kilometer long section. This phenomenon shows that the speed - density based macroscopic model does not contain an acceleration criterion. Based on this result, it is necessary to apply a new criterion to the extreme values of the speed change 


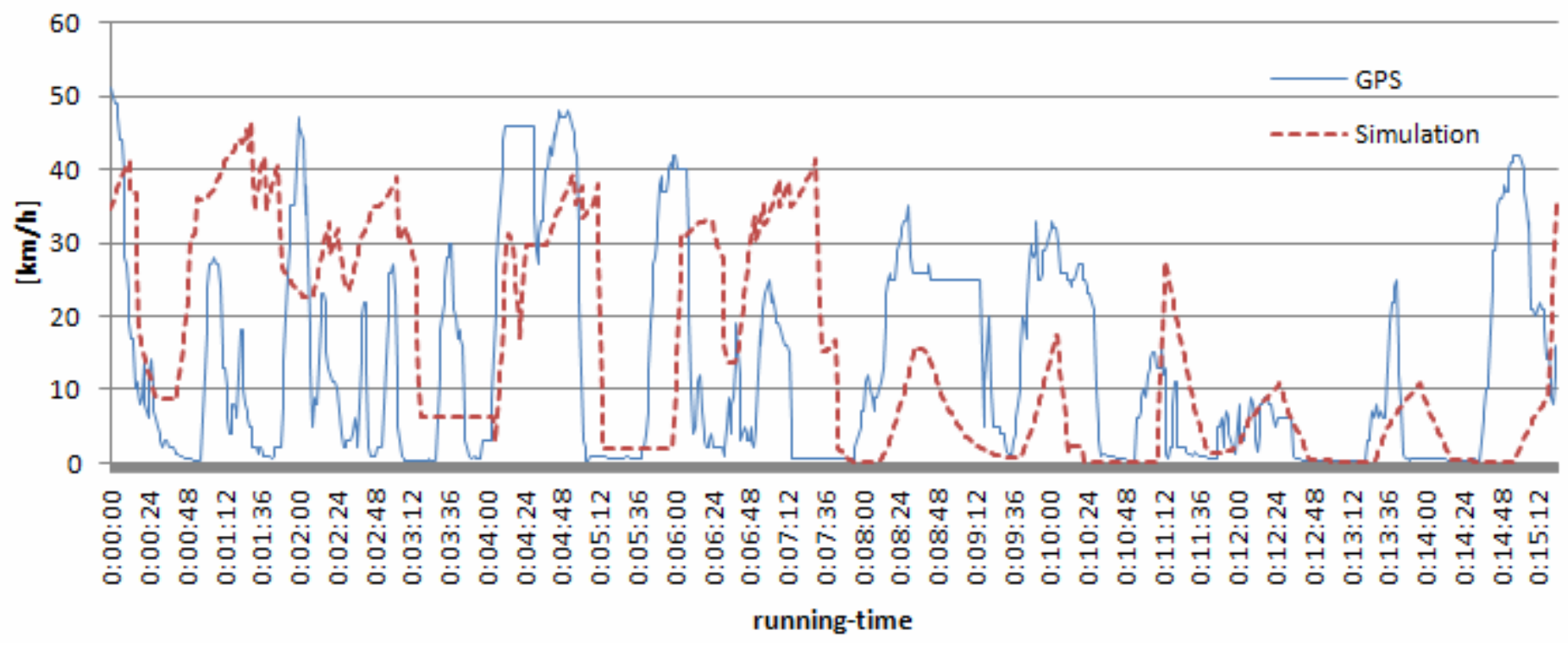

Fig. 1. Example of a speed profile obtained from the simulation together with measured GPS profile 4 5]

in the model, providing that the accelerations remain in the permissible range.

$$
\begin{array}{r}
x(t)_{(n \times 1)}^{\prime}=<1 / l_{i}>_{(n \times n)}\left[K_{(n \times n)} \times(t)_{(n \times 1)}\right. \\
\left.+K_{i n p(n \times m)} S(t)_{(m \times 1)}\right]
\end{array}
$$

The new criterion in a discreet model applying $\Delta t$ step:

$$
\begin{aligned}
& \text { If } v_{i}(t)^{\prime}>a_{\max }, \text { then: } v_{i}(t+\Delta t)= \\
& =v_{i}(t)+a_{\max } \Delta t(i=1,2, \ldots, n)
\end{aligned}
$$

$$
\begin{array}{r}
\text { If } v_{i}(t)^{\prime}<a_{\min }, \text { then: } v_{i}(t+\Delta t)= \\
v_{i}(t)+a_{\min } \Delta t(i=1,2, \ldots, n)
\end{array}
$$

Where: $v_{i}(t)$ on the $i^{t h}$ section is the calculated speed of traffic, $a_{\min } \approx-3,5 \ldots-4 \mathrm{~m} / \mathrm{s}^{2}, a_{\max } \approx 1,8 \mathrm{~m} / \mathrm{s}^{2}$.

On the next figures we present a measured speed profile recorded at peak time traffic. On Fig. 2 a continuous line shows the speed profile simulated with heavy traffic in peak time, and dashed line shows the values after filtering out the unrealistic big acceleration or deceleration values. Diagram b. represents the full speed profile after filtering. Similarly to this, figures c. and d. show the acceleration diagram with the original and with the filtered data, and the acceleration profile after filtering. Fig. 22, shows the percentage distribution of the acceleration values.

Based on the acceleration profiles it can be stated, that our simulation model gives bad values only in case of sudden acceleration or deceleration. A speed profile sampled every second and the acceleration profile calculated from it consists of 6001200 points, while bad values occur in 5-25 points only, which is about $2-4 \%$.

\section{Resume}

We filtered out the unreal acceleration and deceleration values, and recalculated the speed- and acceleration profiles. We experienced that there is an insignificant difference between the original and filtered speed profiles (the calculated difference is $0,46 \%$ for the full time; 5,68\% for the critical points). The conclusion is that the effect of the filtering on the statistician processes examined by the macroscopic traffic model is insignificant.

However, when obtaining optimal routes (optimal trajectory) from the model it is important to ensure that there are no unreal acceleration values in the calculated speed and acceleration profiles! So, filtering is important when switching to microscopic models.

The phenomenon recognized here points out an interesting new problem connected to the macroscopic traffic models. The elimination of this phenomenon resulted the development of the model. We changed the model so, that it examines the acceleration values in every time point, and if one of them is outside the permissible range then the acceleration value will be limited. The model will process this modified speed function.

\section{References}

1 The technical analysis of alternative folding systems, 2009. Research meaning, BME Advanced Vehicle Control Knowledge Centre, Budapest.

2 Péter T, Bokor J, For large road traffic networks' non-linear model hipermatrix of contact, Vehicle of Future 2007/1-2.

3 Péter T, Stróbl A, Fazekas S, Software process analysis, large road traffic networks optimising, Vehicle of Future 2007/1-2.

4 Bede Zs, Péter T, Egyedi sebességfolyamatok kinyerése, nagyméretü városi úthálózatok modellezése során,.

5 _ The Extraction of Unique Velocity Processes from a Macro Model, Periodica Polytechnica Ser. Transp. Eng 38 (2010), no. 1, 3-8, DOI 10.3311/pp.tr.2010-1.01. 


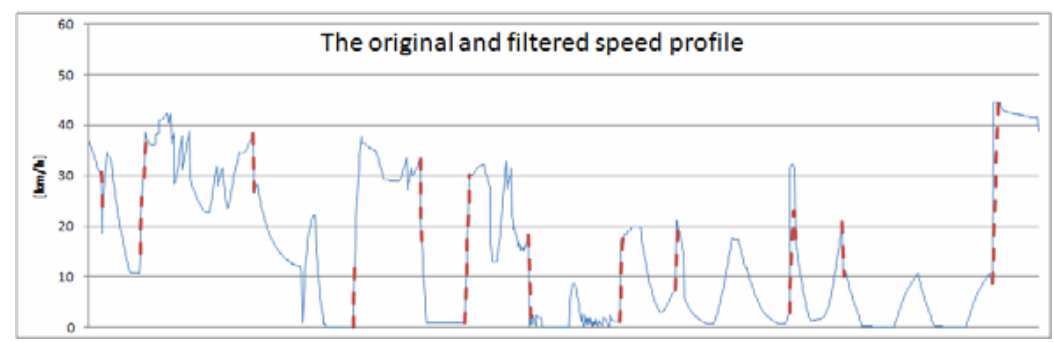

a)

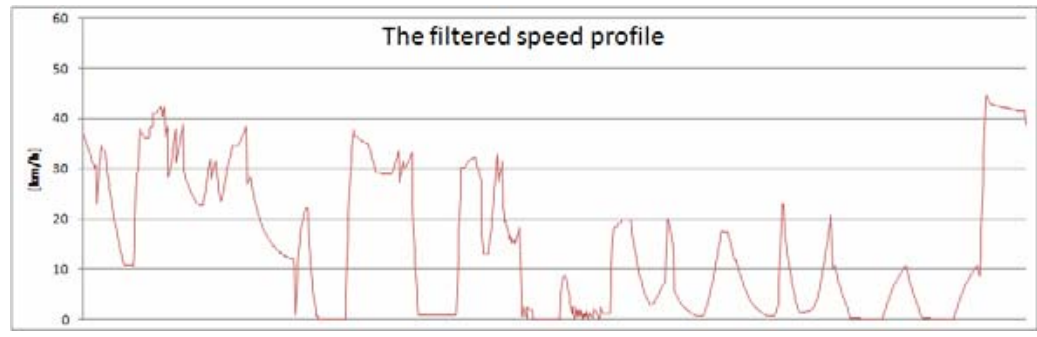

b)

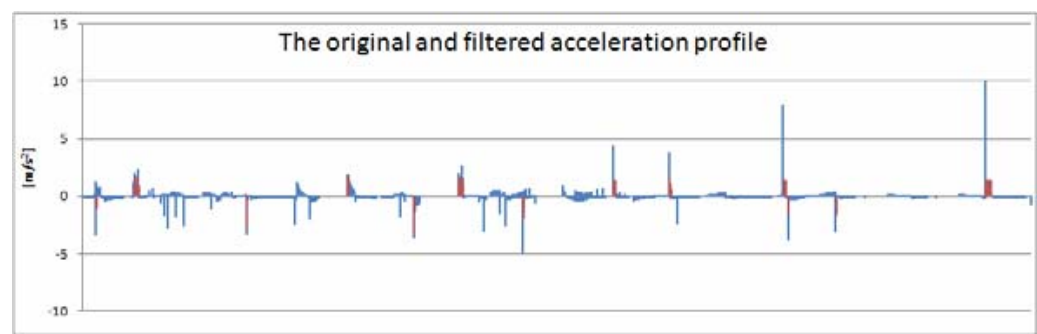

c)

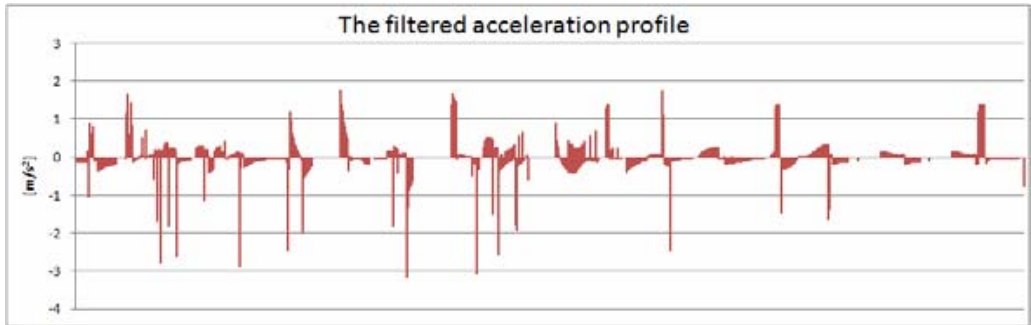

d)

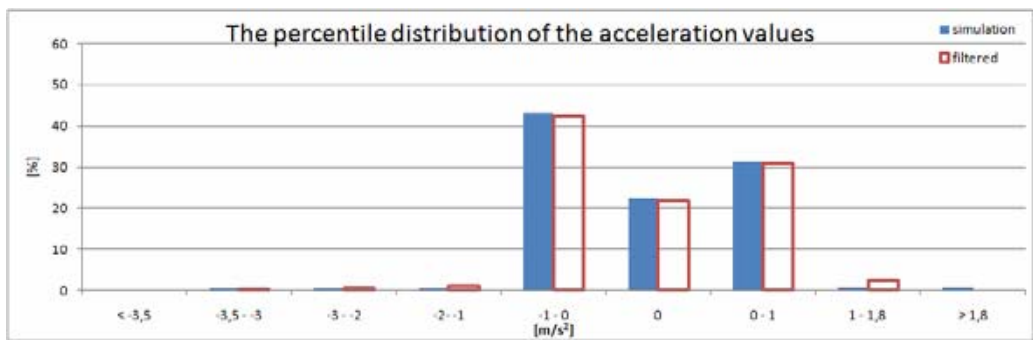

e)

Fig. 2. A simulation heavy traffic, the original and filtered speed and acceleration values, and the percentile distribution of the acceleration values 